\title{
Knowledge of Hygienic Practices among the Kitchen Staff in Second Cycle Institutions in Kumasi Ghana
}

\author{
Asamoah Margaret \\ Matron, Opoku Ware Senior High School, Kumasi \\ Hagan Adwoa J \\ Lecturer, Takoradi Technical University \\ Department of Hospitality Management, Takoradi \\ Commey Vida \\ Senior Lecturer, Kumasi Technical University \\ Department of Hospitality Management, Kumasi
}

\begin{abstract}
This study examined food safety practices among the kitchen staff in second cycle institutions in the Kumasi metropolis and aimed at evaluating the knowledge and attitudes of matrons, cooks and pantry hands in second cycle institutions on hygienic practices, and their perspectives on the effect of individual hygiene on food contamination. The researchers employed a mixed methodology as the research design-using questionnaire and in-depth interviews as instruments to collect data from kitchen staff members of Opoku Ware and St. Louis Girls' Senior High Schools. The study found that, even though about $62 \%$ of the respondents have had no formal training in food safety practices prior to their recruitment, they however consider training as very crucial to the work of food preparation, food handling, as well as methods and processes of food preservation. As a result, they appreciate the need for constant training and workshops, and are as well prepared to participate in such trainings to build upon their knowledge on food safety and hygienic practices. The study also revealed that the kitchen staff members of the two institutions are conscious of personal hygiene and thus consider regular washing of hands with soap as one critical way of avoiding food contamination. The study, finally recommends periodic medical checks, in-service training on food handling and the use of protective clothing by staff in all schools to ensure food safety and hygienic practices in school kitchens.
\end{abstract}

Keywords: Hygienic Practices, Food contamination, Kitchen Staff, Senior High Schools, Food Safety

\section{INTRODUCTION}

Food is an important basic necessity; it is a critical contributor to physical well-being and a major source of it. Pleasure Rozin, Lowery, Imada, and Haidt (1999) opined that, food procurement, preparation and consumption are vital for sustenance of life. Due to this importance of food, it is important that the preparation of it be done in a very clean environment and must contain all nutritional components. However, diseases spread through food are common and persistent problems that result in appreciable morbidity and death (Chukwuocha et al., 2009; Newell et al., 2010). Food-borne illnesses have been described as one of the most widespread problems of the contemporary world (Newell et al., 2010). 
Unnevehr (2000), asserts that food contamination is an important and growing public health and economic problem in many countries. Food contamination in developing countries is caused by many factors including traditional food processing methods, inappropriate holding temperatures, and poor personal hygiene of food handlers.

Further, Monney, Agyei, and Owusu (2013) asserts that the prevalence of food-borne illnesses in developing countries is intertwined with other economic and developmental issues, namely: legislation, infrastructure and enforcement mechanisms. Specific examples include inadequacy of food safety laws, laxity in regulatory enforcements, and the lack of education for food handlers.

Food safety is therefore one of the most pressing health and safety issues facing most developing countries since it leads to both public health and social consequences. According to Afele (2006) everyone is at risk to contract a food-borne illness, but those at higher risk include the elderly, young children, pregnant women, transplant recipients, and the immunocompromised, because their immune systems are either not fully developed or are compromised by a weakened condition.

Second cycle institutions in Ghana are the next level of education one goes through immediately after basic education. Students in second cycle institutions are either boarding or non-boarding. Boarding students, according to Boarders (2013), spend their entire term in school and only go home during vacations. On the other hand, day students (non-boarding) stay with their parents and guardians and spend only six hours in school. Students who are in second cycle institutions are normally between the ages of 14 and 18 years. To Iyer, Bhoite, and Roy (2011), well managed boarding schools provide good nutrition, hygiene, sanitation, a balanced daily routine of personal care, sport and recreation and study habits that children introduce to their own home and families and to their lives as adults.

When it comes to school setting, food safety is much more important because it has direct effect on their academic performance. Dawso Van Druff (2012) affirms that preventing foodborne illness is an important concern in school settings because outbreaks have personal, academic, financial, and legal consequences for each school district. He maintains that student absenteeism affects students' performance in school, and that food-borne outbreak of epidemic may also result in closure of schools. Students are an at-risk population and can contract foodborne illness from eating or drinking a contaminated substance.

Food handlers or the people who are directly involved in the preparation and production of foodstuffs are therefore integral in reducing food-safety risk (Asiegbu, 2015; Tirado, Clarke, Jaykus, McQuatters-Gollop, \& Frank, 2010) . The most commonly associated food handling practices identified in school-related outbreaks were improper temperatures for storage and holding food and food contamination by staff (Sauer, 2014).

According to Unnevehr (2000), the World Health Organisation (WHO) has developed five main keys to safer food, which comprise keeping cleaning, separating raw and cooked food, cooking thoroughly, keeping food at safe temperatures, and using safe water and raw materials This is to say that not observing any one of them can lead to the food being unsafe for consumption. For instance, even when the environment where the food is prepared is hygienic and the food is not cooked well, it can lead to food contamination (Unnevehr, 2000). 
Several studies, (Mensah, Yeboah-Manu, Owusu-Darko, \& Ablordey, 2002; Newell et al., 2010) conducted on the knowledge of food safety and practices have mostly concentrated on street food safety. For instance, Samapundo, Climat, Xhaferi, and Devlieghere (2015) did a study of food vendors and safety practices and through questionnaires they found out that most of the food vendors were uneducated and therefore had little knowledge on food safety practices.

Although the importance of school feeding in health and nutrition is well established, little work has been done on the safety of foods consumed by students in second cycle boarding institutions in Ghana. This study therefore sought to assess the knowledge and attitudes of matrons, cooks and pantry hands in second cycle institutions on food safety practices and how their knowledge can affect foods consumed by students in these institutions.

\section{Study design, area and sample}

\section{MATERIALS AND METHODS}

The study was a descriptive survey conducted on the kitchen staff of both Opoku Ware Senior High School and St. Louis Senior High School in the Ashanti Region of Ghana. The target population for the study was kitchen staff which comprised of matrons, cooks and pantry hands. These were selected because they prepare meals for students in these boarding houses of senior high schools. Using a purposive sampling technique, 54 respondents were used.

\section{Data Collection Instruments and analysis}

Semi- structured interview guide and a pre-tested structured questionnaire were used to collect data from respondents. These were used to enable the researcher explore the perspectives and points of view of respondents. The questionnaire consisted of both open and close ended questions based on the objectives of the study.

\section{RESULTS AND DISCUSSION}

Table 1. Frequency table of the educational background of kitchen staff in St. Louis and Opoku Ware Senior High Schools.

\begin{tabular}{lll}
\hline Level of Education & Frequency & Percentage (\%) \\
\hline & & \\
Not Educated & 10 & 20 \\
Primary & 21 & 42 \\
Secondary & 15 & 30 \\
Tertiary & 4 & 8 \\
\hline Total & 50 & 100
\end{tabular}

Source: Researcher's field data (2015)

Table 1 above shows the educational background of the respondents, it is can be seen that 42 percent and 30 percent of the respondents had primary and secondary education respectively, 20 percent had tertiary education and only a few 8 percent had no formal education. The differences in the educational levels of the various respondents obviously will determine the perspective of each of the staff members with respect to their perception and knowledge of food safety practices. 
Table 2. Distribution of respondents on being medically screened before offered employment

\begin{tabular}{lll}
\hline Medical Examination & Frequency & Percentage (\%) \\
\hline & & \\
YES & 39 & 78 \\
NO & 11 & 22 \\
\hline Total & 50 & 100
\end{tabular}

Source: Researcher's field data (2015)

Table 2 above shows responses on whether respondents were medically screened before offered employment to be food handlers at the schools. Majority of the respondents, 78 percent said they were medically screened before being offered employment and 22 percent said they were not screened. This is laudable as it is in compliance with Section 286 of the Criminal Code (Dwumfour-Asare, 2015).

Table 3. Response on whether personnel go through periodic medical examination after recruitment

\begin{tabular}{lll}
\hline Periodic Medical & Frequency & Percentage (\%) \\
\hline Yes & 33 & 66 \\
NO & 17 & 34
\end{tabular}

TOTAL $\quad 50 \quad 100$

Source: Researcher's field data (2015)

On the issue of whether respondents undergo periodic medical examination after their recruitment, Table 3 shows that 66 percent undergo periodic medical examination whiles 34 percent said they had never gone through any medical examination after recruitment. The lack of commitment on the part of this significant percentage of respondents not undergoing through periodic medical screening is a threat to food safety as many of them might be agents of food borne illnesses unawares.

\section{Responses of interviewees on the need for formal training for School Kitchen Staff Members}

The use of in-depth interview as the second data collection instrument besides questionnaire to ascertain respondents' views on the need for formal training for kitchen staff members generated several responses:

Out of the total number of six people randomly interviewed, two of the respondents had secondary education in Home Economics that made them formally trained in food safety practices; one of the respondents had only primary education but had gone through some form of training prior to recruitment, whiles three had no formal education but had been working as cooks and pantry hands over two decades.

Respondent "A" said: Formal training is very important when it comes to cooking for students because it helps you to first of all understand the importance of food and nutrition, and also the skill to be able to know the nutritional value of whatever food substance you use to prepare food for students, the kind of diet that is appropriate at any given time. 
Respondent "B," who had been working for 21 years as a cook but had no formal education said formal training for persons before their recruitment as kitchen staff members in the second cycle institutions is critical because it helps one to acquire basic management skills needed to manage as a matron, and also be able to apply the skills acquired in ensuring safety practices when it comes to food handling and food preservation.

Another interviewee, who the researchers identified as Respondent " $C$ " was of the view that training is important because it helps one to be conscious of hygiene and food safety practices which if adhered to, reduces the risk of food contamination that sometimes results in the spread of foodborne diseases that pose health risks to students.

In her view, in-service training for kitchen staff members should be a regular practice Said Respondent "D".

The need for formal training for persons in the foodservice industry as in the case of matrons, cooks and pantry hands in the kitchen departments of educational institutions is supported by literature (Newell et al., 2010; Rozin et al., 1999).

The researchers therefore think that inasmuch as training is necessary for kitchen staff members in second cycle institutions in the Kumasi metropolis and the nation at large for that matter, there is also the need to let kitchen staff members who undergo such formal trainings to understand the purpose of such trainings.

\section{How respondents' individual hygiene affect foods prepared at these educational institutions}

The second research question sought to investigate how individual hygiene of matrons, cooks and pantry hands affect foods prepared in second cycle educational institutions in the Kumasi metropolis. This research question was analysed by taking into account respondents' awareness about personal hygiene and the frequency in which such personal hygiene practices are observed before, during and after respondents come into contact with foods.

Table 4. Response on whether respondents wear gloves before handling Ready-to-Eat Foods

Wearing gloves when Frequency Percentage (\%)
handling food

\begin{tabular}{lll}
\hline & & \\
YES & 11 & 22 \\
No & 26 & 52 \\
Sometimes & 13 & 26 \\
& & \\
\hline Total & 50 & 100 \\
\hline
\end{tabular}

From table 4 above, about 52 percent of kitchen staff members in second cycle institutions in the Kumasi metropolis do not wear gloves before handling ready-to-eat foods served to students in boarding institutions and 26 percent said the occasionally wear gloves when handling ready to eat foods only about 22 percent indicated that they wear gloves when handling ready to- eat- foods. From the table above, it can also be seen that the percentage of kitchen staff members who wear gloves before handling ready-to-eat food is not encouraging 
as it falls below those who occasionally do so. This means that staff can easily contaminate cooked food by handling with bare hands which can translate to food borne illness.

Table 5. Frequency table of personnel who wash their hands with soap and water after visiting the washroom.

Hand washing with water \& Frequency Percentage (\%)

Soap

\begin{tabular}{lll} 
Yes & 47 & 94 \\
Not all the time & 3 & 6 \\
No & 0 & 0 \\
\hline Total & 50 & 100 \\
\hline
\end{tabular}

Source: Researcher's field data (2015)

The question of whether staff members observe personal hygiene by regularly washing their hands with water and soap anytime they visit the washroom when on duty elicited varied responses. From the table 5 above, a significant number of 47 representing 94 percent of the respondents said they wash their hands with water and soap anytime they visited the washroom, whereas only 3 respondents, constituting 6 percent indicated that they occasionally washed their hands with water and soap.

What the data in the table above imply is that, the practice of washing hands with water and soap is a personal hygiene culture observed by almost all kitchen staff members in second cycle institutions in the Kumasi metropolis. This personal hygiene practice by the kitchen members is in compliance with Edima, Tem Nnam, Awono Enama, Biloa, and Ndjouenkeu (2014) who stressed the need for food handlers to endeavor to practice regular hand washing with water and soap.

The researcher also used an in-depth interview as the second data collection instrument for data collection. This method sought the perspectives of respondents on the importance of individual hygiene, and why they observe personal hygiene practices such as regular washing of hands with water and soap anytime they visit the washroom, and keeping their finger nails short and clean, and how those practices affect the safety of foods prepared for students in educational institutions. The responses generated from the interview have been categorised into themes discussed below:

\section{Avoid Food Contamination}

The respondents interviewed unanimously stressed the need for proper personal hygiene within and without the parameters of the kitchen in which they cook for boarders. This, according to the respondents, is to avoid food contamination.

Respondent " $A$ " said that observing personal hygiene does affect the foods prepared for boarders in second cycle institutions in Ghana. This is because even though I do not have formal education, I know from so many years of working as a cook that food can be contaminated if cooks who prepare and handle food have their hands contaminated. As cooks therefore, promoting personal hygiene goes a long way to reduce the spread of food 
contamination. We are therefore conscious of the need to ensure personal hygiene before getting into contact with food.

Another respondent also pointed out the effect of personal hygiene on food safety from professional point of view by explaining that one responsibility on the part of a domestic matron is to ensure that the kitchen and its environments are clean, and the need to ensure that staff members adhere to personal hygiene practices to ensure the safety of food. This, she believes, is the hallmark of a competent domestic matron (Respondent B).

Others also were of the view that personal hygiene practices should not only be observed under supervision, but it must be a routine practice and consciously done if one wants to stay healthy. They believe that personal hygiene helps to protect the health of both kitchen staff and students they prepare food (Respondent "C")

My duty as a domestic matron is to ensure that I practice personal hygiene first, then I can insist all other staff members-cooks and pantry hands to do same. The reason is that, the fate of thousands of students in the boarding house system is in our hands. Their parents have entrusted these children in the hands of school authorities, and they also expect that we provide them with wholesome foods that will ensure their health and safety. What then happens if there is an outbreak of epidemic as a result of food contamination from our end? This is why observing personal hygiene is critical in our work (Respondent "D").

Basic personal hygiene practices such as keeping short and clean finger nails, using hand gloves when handling some kind of foods, as well as conscious washing of hands after visiting the washroom promote food safety and reduces the risk of the spread of foodborne illnesses. These agree with Dawso Van Druff (2012) who affirms that preventing food-borne illness is an important concern in school settings because outbreaks have personal, academic, financial, and legal consequences for each school district.

\section{CONCLUSIONS AND RECOMMENDATIONS}

The study revealed that though majority of the kitchen staff members recruited had primary and secondary school education as their highest qualification, they had fair knowledge of the importance of practicing hygiene when preparing meals for boarders in the secondary schools. Majority had gone through medical examination before being employed, while 66 percent of the staff members do periodic screening. 94 percent of respondents considered handing washing with soap as one critical way of reducing food contamination. Also majority of the respondents were prepared to undergo in-service training to upgrade their knowledge and skills on food safety and personal hygiene.

\section{RECOMMENDATIONS}

Since the health of the food handler is critical to the safety of food prepared for consumers, it is recommended that periodic medical screening of food handlers in the second cycle schools be prioritized as one of the requirements for working in the kitchen environment.

Periodic in-service training on food safety must be organized for kitchen staff members to remind them on importance of practicing personal, kitchen and food hygiene and also update them on current issues relating to food safety. 


\section{REFERENCES}

Afele, M. (2006). Street food boom in Ghana spurs calls for better hygiene. Bulletin of the World Health Organization, $84(10)$.

Asiegbu, C. V. (2015). The food safety knowledge and microbial hazards awareness of consumers of ready-to-eat street-vended foods and their exposure to microbiological hazard.

Boarsrde, N. S. O. (2013). a comparative study of the dietary intake and nutritional status of boarders and nonboarders in selected second cycle institutions within the tamale metropolis. department of community nutrition of the school of medicine and health sciences, university for development studies.

Chukwuocha, U., Dozie, I., Amadi, A., Nwankwo, B., Ukaga, C., Aguwa, O., . . Nwoke, E. (2009). The knowledge, attitude and practices of food handlers in food sanitation in a metropolis in south eastern Nigeria. East African journal of public health, 6(3).

Dawso Van Druff, C. A. (2012). Implementation of school districts' food safety plans and perceptions of support for food safety and training in child nutrition programs in one USDA region.

Dwumfour-Asare, B. (2015). Effect of local authorities' field monitoring visits on awareness of regulation and hygiene practices among street food vendors: the case of two district capitals in Ghana. Journal of Behavioral Health, 4(3).

Edima, H., Tem Nnam, R., Awono Enama, T., Biloa, D., \& Ndjouenkeu, R. (2014). Case Study of the Street Food Sector in the Metropolitan Areas of a Cameroonian City, Yaounde. Int. J. Curr. Microbiol. App. Sci, 3(9).

Iyer, U. M., Bhoite, R. M., \& Roy, S. (2011). An exploratory study on the nutritional status and determinants of malnutrition of urban and rural adolescent children (12-16) years of Vadodara city.

Mensah, P., Yeboah-Manu, D., Owusu-Darko, K., \& Ablordey, A. (2002). Street foods in Accra, Ghana: how safe are they? Bulletin of the World Health Organization, 80(7).

Monney, I., Agyei, D., \& Owusu, W. (2013). Hygienic practices among food vendors in educational institutions in Ghana: the case of Konongo. Foods, 2(3).

Newell, D. G., Koopmans, M., Verhoef, L., Duizer, E., Aidara-Kane, A., Sprong, H., ... Scheutz, F. (2010). Food-borne diseases-the challenges of 20years ago still persist while new ones continue to emerge. International journal of food microbiology, 139, S3-S15.

Rozin, P., Lowery, L., Imada, S., \& Haidt, J. (1999). The CAD triad hypothesis: a mapping between three moral emotions (contempt, anger, disgust) and three moral codes (community, autonomy, divinity). Journal of personality and social psychology, 76(4).

Samapundo, S., Climat, R., Xhaferi, R., \& Devlieghere, F. (2015). Food safety knowledge, attitudes and practices of street food vendors and consumers in Port-au-Prince, Haiti. Food control, 50.

Sauer, K. (2014). Food Safety in Schools. Food Safety: Researching the Hazard in Hazardous Foods, 323.

Tirado, M., Clarke, R., Jaykus, L., McQuatters-Gollop, A., \& Frank, J. (2010). Climate change and food safety: A review. Food Research International, 43(7).

Unnevehr, L. J. (2000). Food safety issues and fresh food product exports from LDCs. Agricultural Economics, $23(3)$. 